\title{
Oromo Proverbs: The Analysis of Context, Value, and Syntax
}

\author{
Amensisa Wakuma Rundassa, Lecturer \\ English Language \& Literature Department, Arsi University \\ Ethiopia
}

\begin{abstract}
The purpose of this study was to investigate the of proverbs in the act of conversations among the Oromo people. Oromo proverbs were then under close scrutiny of context, value, and syntax. In so doing, the qualitative research method that stems from realist ethnography was put to use so as to encapsulate its purpose. Afterwards, the investigation was carried out using a total of $(n=116)$ from the Arsi Oromo inhabited Kersa and its vicinity in Arsi zone, Ethiopia. Of this amount, thus, $(n=78(67 \%)$, male; $n=38(33 \%)$ female) involved voluntarily. To catch up the research agenda, purposive sampling was used as a means of selecting the participants whereby age was a requirement. In the quest, the research subsequently used three instruments: participant observation, interview, and field notes. The findings therefore hereby show that contexts and values are embedded in proverbs though their linguistic analysis entirely rely on scholarly accomplishment. In these realities are explicated three paradoxical nature of proverbs - brevity, acculturation, and social control. At last, recommendations and implications are given so that the outcomes of the study will aid in the enactments.
\end{abstract}

Keywords:- context, culture, value.

\begin{tabular}{|c|c|}
\hline \multicolumn{2}{|c|}{ Acronyms and Abbreviations } \\
\hline e.g., & for example \\
\hline i.e., & that is \\
\hline $\mathbf{L}_{1}$ & First Language \\
\hline $\mathbf{L}_{2}$ & Second Language \\
\hline ORS & Oromia Regional State \\
\hline
\end{tabular}

$\begin{array}{lc}\text { Glossary } & \\ \text { Abbaa } & \text { father } \\ \text { Ayyana } & \text { Ceremony, rit } \\ \text { Bokku } & \text { club, scepter } \\ \text { Chaffe } & \text { grassy place } \\ \text { Eebba } & \text { blessing } \\ \text { Gadaa } & \text { the system } \\ \text { democratic institution } \\ \text { Jila } & \text { a main ritual } \\ \text { Seera } & \text { law } \\ \text { Waaqa } & \text { God }\end{array}$

Glossary

Ayyana Ceremony, ritual

Bokku club, scepter

Chaffe grassy place

blessing

democratic institution

Jila a main ritual

Waaqa God

\section{INTRODUCTION}

\section{Background}

Proverbs are an integral part of oral literature, and of all they help us clarify, or elucidate, or delineate meanings, and Oromo proverbs are no exception. Within this context the term "Oromo" attributes one of the largest Cushiticspeaking people in Ethiopia. Rowoldt (2018, p.19) said, "Oromo (i.e., Afan Oromo) is an East Cushitic tongue of the Afro-Asiatic language family written in either the ancient Geez script or a modified Latin alphabet named Qubee." On the basis of this, of course, it is of fundamental importance to indicate the language is defining the identity of the Oromo people by which proverbs play a significant role.

By the same token, scholars have already been trying to gain insights into the definition of a proverb. For instance, "Proverb means," say Brown \& Miller (2013), "a memorable saying expressing a perceived truth or moral lesson" (p.365). If this is all, truths or moral lessons are certainly designating facts intact. Adding further definition, Finnegan (2012) once said, "Proverbs are a rich source of imagery and succinct expression on which more elaborate forms can be drawn" (p. 379). Having these definitions, the study solemnly discusses the context, values, and syntax where three elements, i.e., research, registry, and institution are the heart of the problem and will be discussed shortly under this heading.

Context embarks on proverbs; and on the other, proverbs can't preclude context. As Seitel (1999) points out, "In proverb speaking, contextualization is a necessary component of logical form: A topic of conversation is described through metaphorical reference to the situation portrayed in a proverb text" (p.5). Similarly, "The apparent incongruence between the context and the utterance," Dominguez (2010, p.50) says that "alerts the listener to the potential use of a proverb..." Thus, proverbs barely exist independent of contexts.

Moreover, proverbs are value laden. "Values," Collins and Patricia (2003) defined, "are qualities based on normative judgments of good and bad, and in which there is an emotional investment" (p. 371). Under no circumstances, good values are obligatory and mustn't be violated. For instance, the antisocial behaviors, (e.g., murder, theft, burglary, betrayal, unfaithfulness, abduction, rape, and so forth) are prohibited. 
At last, syntax herewith is to mean the pace out of proverbs in accordance with their grammatical syntactic construction. Judging from ordinary conversation, proverbs do have both mysterious and definitive structural length. Montgomery \& et al. (2007) say, "Conversation is full of false starts, repetitions, pauses, unfinished sentences and self-correcting, so real-time speech can look messy." (p.275) Hence, thereof undeniable realities in proverbs. Moreover, as a part and parcel of folklore, Tankersley (2006, p.44) asserts that proverbs have a definite and recognizable structure. In a nutshell, the broad and all encompassing definitions of proverbs clearly and completely encapsulate the basic facts of context, value, and syntactic elements.

\section{Statement of the problem}

As Oromo proverb says, "Problems stay with a person until they are resolved." In a similar analysis, referring to the same problem, time and again, has never been fully effected as to the long-standing problems of Oromo proverbs. Miraculously, in so far in Ethiopia, the downfall of derg (military regime) in 1983 E.C (May 1991), built high hopes to the overall developments of Oromo language; and the era, clearly declared the legitimacy of Latin alphabet to the language. This time onwards, the plethora of literary works in the language, i.e., journals, newspapers, novels, and so on were seemed to gain momentum. But the development hadn't had a continuing impulse as of its start, and as a result, the challenges remained intact. Therefore, the study needs to articulate the problem solely from three focal points: lack of research, lack of registry, and lack of institution.

Firstly, lack of research is to refer the past research attempts. Either little or no empirical researches have been able to witness the role of Oromo proverbs as far as contexts and values are being taken into account. In effect, the lack of insightful analysis has kept terrible happenings as to what else is to be honored in them. The point is that so much less is known of the facts therein. In a nutshell, empirical research hadn't held forth fundamental and gratefully acknowledged contributions.

Secondly, in so far, Oromo proverbs traversed long, hard and tragic roads. However, the language is now being operated as an academic language, though little has been done to salvage or collect as a preservative effort. To be honest, very few have got into print, or witnessed the journey (e.g., Cotter, 1990; Sumner, 1996, and others). Numerous of the proverbs have therefore been either discarded or left unaccounted-for. Take, in other languages (e.g., English) proverbs had started entering into collections since the $16^{\text {th }}$ century (e.g. Mieder, 2004). The claim is therefore based on insightful conclusions, and no valid reason why such potential priority areas deprived of attention.
Thirdly, institutions execute societal goals, and so do efficient and better managed entities; nevertheless, existing institutions, perhaps for different reasons out of the scope of this study, do not seem to cope with such a position. Of great importance in this connection is a looming crisis as long as the assortment of proverbs is attested. Thus, the study hereby wants to investigate the major drawback, especially why the anthology of proverbs are still absent at a desired level in the history of Oromo language. As a general conclusion, there is a very societal anxiety as to the backlash of inadequately capacitated institutions to execute responsibilities. To this end, therefore, the institutions should travel long to carefully address and orchestrate the specific problems of Oromo proverbs.

\section{$>$ Objectives of the study}

The primary goal of the study is to delineate the role of Oromo proverbs in the history of Oromo culture in their day-to-day oral conversations; in this regard, therefore its explicit objectives are to:

- identify the contexts couple on by proverbs;

- enquire values ascertained by proverbs;

- determine the syntax of some proverbs;

- enlighten about the status of Oromo proverbs.

\section{$>$ Research questions}

As far as proverbs are concerned, the overarching questions of the study are as follows:

- Do contexts venture upon proverbs?

- What sort of cultural values are blended?

- What linguistic structure can be indicative?

- Why do proverbs used in conversations?

- What should be improved?

Indeed, at the very outset of the study, it is these research questions that would require apt answers so that compatible move can be ascertained from its findings and recommendations.

\section{$>$ Significance of the study}

Why is then this research? Below are three fundamental reasons:

- It investigates how proverbs enliven contexts of conversations;

- It indicates what sort of value system embedded in proverbs;

- It designates the mystifying structure of some proverbs;

- It addresses the why of proverbs in conversations;

\section{$>$ Delimitation of the study}

This was a lengthened study carried out in the boundary of Munessa district, Arsi zone, Oromia Regional State (henceforth, ORS), Ethiopia. Nonetheless, it is apparent that the culture of using proverbs seems universal throughout ORS; indeed, due to some practical reasons the findings of this study won't posit universality in any way other than this district. Thus, the study is bounded to the above-mentioned district and the results can't be generalized to similar linguistic contexts. 


\section{Scope \& limitation of the study}

Due to short of finance, its scope is limited to a district of ORS. Three points to remark: financial constraints, sampling bias, and measuring instruments. Though the financial issue is obvious, from the standpoint of potential knowledge in using proverbs, age was used as a prerequisite for the sampling the focal participants. Similarly, the instruments used in the study can't be free of drawbacks. Bearing these pitfalls and the nature of qualitative research in mind, therefore, it is impossible to say the study is perfectly free of constraints.

\section{$>$ Operational definitions}

- Context - The term context is used to refer to the diverse elements-for example, persons, groups, institutions, history, economic and political factors, features of the physical environment - that influence the behavior and beliefs of individuals or groups. Context also refers to the cultural, historical, political, and social ties that connect individuals, organizations, or institutions (LeCompte \& Schensul, 2010, p.31)

- Culture - consists of the beliefs, behaviors, norms, attitudes, social arrangements, and forms of expression and production that form a describable pattern in the life of members of a community or institution (LeCompte \& Schensul, 2010, p.33)

- Values - are ethical principles and ideals or the statements of what should be, rather than of what is (Bruce \& Yearley, 2006, .p.313).

\section{LITERATURE REVIEW}

Some studies have the stand that culture is hard to define (e.g., Spencer-Oatey \& Franklin, 2009). Still, some other studies deny the existence of culture (e.g., Biehl \& Good, 2007, p.7). However, based on the majority of empirical evidences proverbs barely been received researchers' attention as compared to what they serve in human day-to-day interaction. They exist everywhere. According to Finnegan (2012), for instance, "Proverbs seem to occur almost everywhere in Africa" (p.379). In support of this, Stone (2006, p. 12) notes that "proverbs are common to nearly all cultures, of both ancient and modern, literate and non-literate." Thus, proverbs are said to be powerful, universal, and symbolic feature of conversations among the Oromo people.

Today, in spite of their ubiquitousness, however, little is known about the fate of existing Oromo proverbs. People simply use them as if they held nothing in entering into their discussions, i.e., pair discussions, social gatherings, and so forth. In light of this evidence, Heigham \& Croker (2009, p. 93) explain that "through ethnographic studies, researchers look at cultures for what people do (behaviors), what they say (language), the potential tension between what they do and ought to do, and what they make and use, such as artifacts." Therefore, research has to bridge the gaps being noticed over time. Of all things, therefore, the study hereinafter sheds light on the following underlying elements: context, value, and syntax.

\section{$>$ Context}

Context is ostensive (or instructive) in the area of (applied) linguistics, and Kleinman (2006, p.1) said, "There are proverbs for every imaginable context." Thus, contexts apparently rested in the interest of giving clues as far as proverbs able to establish them. Bauman (1983; cited in Bauman and Briggs, 1990) says, "The constitutive of context are 'context of meaning,' 'institutional context,' 'context of communicative system,' 'social base,' 'individual context,' and 'context of situation.'”(p. 61). So, oftentimes, therewithal is a proverb that fit into the context. Proverbs are implanted in contexts, and contextualization makes and helps proverbs indestructible from human mind (i.e., very long lasting).

Furthermore, since proverbs run in pairs the speaker must take care of using them. That is to say, each proverb seems to flare up and hunts for another ideally contradictory proverb. Thus, using incoherent, or incongruent, or decontextualized proverbs could be like a tightrope walk; when this is the case, the consequence can be counterproductive. Roth $\&$ Aberson note that "proverbs may often contradict each other, yet the trick is to use the right proverb at the right time in the right situation" (2008, p. 9). Kleinman (2006, p.1) confirmed Roth \& Aberson's findings, and indicates that proverbs contradict one another as life itself.

Finally, let us behold the given topic with what (Murray \& Hughes, 2008, p.198) said, "Contextualization is the provision of background information as a way of framing and giving meaning and significance of what you say, by putting it into perspective". The harmony which came into being enormously establishes a rapport of the conversants.

\section{$>$ Value}

What sort of values? What is/are the unit of analysis for this purpose? 'Value', in its phrasal juxtaposition, denotes a range of interrelated ideas. In this study, however, only a comprehensive account is mined out of the scattered literary sources. "Values are," as Bruce \& Yearley (2006, p. 313) say, "ethical principles and ideals or the statements of what should be, rather than of what is." Thus, it can be recognized as a moral virtue by which the community is to comply. Moreover, "In its more focused meaning," Kleinman says, "moral refers to our sense of right and wrong" (p.15). At last, value is more meaningfully expressed by using proverbs at a time of conversations.

Value spectrums, therefore, be distinguished, unchallenged, and set forth by the society as self-conceit either in stories or in proverbs, or in parables. Such core values could serve as units of analysis. Dominguez (2010) said, "The subtlety of the presentation of values communicated through proverbs is in itself a reflection of a social value: discretion" (p.104). These are like life, language, tolerance, loyalty, honesty, respect, rationality, objectivity, environment, braveness, integrity, compassion, and so forth; of these, insofar, some have long been 
devoted particular attention where proverbs have key roles to play. Moreover, as Collins \& Patricia (2003) said, "Values may be moral or non-moral in nature and may be judged on instrumental or intrinsic grounds" (pp.371-72). So contained therein are thus this list of values being reacted as motives.

In this step, it is better to sum up by mentioning the intricacy of language, value, and culture. Risager (2007, p.94) notes, "Language pre-eminently embodies the values and meanings of a culture, refers to cultural artifacts and signals the people's cultural identity." This is the central concept to this empirical study.

\section{$>$ Syntax}

Why is syntax? The answer seems clear. Oromo proverbs have both definite and mysterious syntactic structures that require a native speaker's higher level of metalinguistic knowledge. Furthermore, "We shall be interested in structure," Halliday (2007) answers, "because it is the means whereby language operates" (p.43). Therefore, to the context of this study, the structure is to mean the sentence-level of Oromo proverbs. The aforementioned signpost questions thus give us a clue to ponder over the epistemological stances to the evergrowing rapidity and development of studies in sentence structure (e.g.: Makkai \& Melby, 1985; Brinton, 2000; Chomsky, 2006; Halliday, 2007). Simply put, research should further investigate the syntax or the linguistic structure of Oromo proverbs.

Oromo proverbs, perhaps like any other proverbs across the globe, have a complex and mystifying linguistic structure, i.e., ambiguous in meaning and structure. Halliday (2007, p.43) says that "language is structured in the way it is because it has to express meanings that are functionally complex." This has been simply noticed as a spin-off careful analysis into the grammatical structure of Oromo proverbs. Presumably, therefore, it might be difficult to make control of the border of syntactic structure for all proverbs. But as far as the aim of the study is concerned emphasis is being accorded to a sentence level. Below are then a summary of proverb form and function outcoming at sentence level.

\section{- Form}

Oromo proverbs, usually at sentence level, have their own structural features. Basically, "Sentence structures," says Hinkel (2004), " are always dynamic" (p. 67). By the same token, the pattern of the proverbs entails the forms for each. In spite of their moral lesson, the phrases and clauses, and the longevity of sound at the end of verbs, above all, indicate their distinctive form. The sample form of proverbs, i.e., simple, compound, complex, and compoundcomplex structures that were given at a time of data collection would be given a later chapter.

\section{- Function/Meaning}

Many studies have come out of the closet on the functional view of a language; for instance, Brown (2000) says, "Functions are essentially the purposes that we accomplish with language, e.g., stating, requesting, responding, greeting, parting, etc.” (p. 248). Hence, the study needed to give the linguistic reference to what for of each and every proverbial speech. In this context, Olson (1996; cited in Smith \& Pelligrini, 2000) offered an important point:

"A variety of oral statements such as proverbs, adages, aphorisms, riddles, and verse are distinctive not only in that they preserve important cultural information but also in that they are memorable. They tend, however, not to be explicit or to say exactly what they mean; they require context and prior knowledge and wisdom for their interpretation" (p. 10).

In effect, proverbs, with no doubt aid the speakers in meaning making at various linguistic circumstances. Proverbs do a lot. Their multiple functions help speakers to reinforce contexts and values therein before.

As has been aforementioned, it is very important to bear in mind that the meaning and function of some proverbs are not easy to make out. One reason could be as a result of literary archaism; for instance, let us take one from the language. 'Otteen ta mijigetti, haxumaan ta mijigetti, mooqqaan carree ceela.' The nearly word-by-word translation in English is 'Pot the toiled, stirring wood the toiled, a spoon would take the melted butter.' From its English translation the meaning, both at lexical and sentence level, it seems a bit clearer. The function is to advise. However, there are such proverbs when it is difficult to make meanings out of them, by this time, the listener has to enter into hedging for clarifications.

\section{RESEARCH METHODOLOGY}

Under this heading the study area, method, design, population and samples as well as data analysis procedures are in subsequent discussions.

\section{Study Area}

The data collection has taken place in ORS, Arsi zone, Ethiopia. The study has long been prolonged for years; that is to say, the opportunity of gaining access from gatekeepers was more facilitated because the researcher had been working around as a high school teacher and later as a university lecturer. Hence, in this particular case, the Munessa district, which was located south of the zone capital, Asella, was selected due to its potential advantage to the topic of the study. Thus, the participants were from the rural areas of the district capital, Kersa. These places are an earthly paradise whereby preserved dense forest marks as a territorial margin. 


\section{$>$ Methodology}

The methodological approach of the study is qualitative; thence, ethnography is by far better to fit into the methodological framework, i.e., ethnographic inquiry is more appealing to study about proverbs since Oromo proverbs have long been deprived of receiving research attention.

\section{$>$ Design}

Determining research design was one of the preliminary works that provides a clear roadmap to the research (e.g., Yin, 2011; Leavy, 2017). Accordingly, it became an imperative task to make double knot the research design with its purpose. Of all the available designs, therefore, the exploratory research design was used to generate data from culture as an issue of unit of analysis. As best one can be, liveliness of conversations were being noticed in their natural settings. By far, the design helped the researcher to explore proverbial bits that came into being during rituals, mediations, arbitrations and so forth. In these contexts, therefore, the study provided an insight by using the following three instruments: observation, interview, and field notes.

\section{- Observation}

Participant observation was used once in a while; and most importantly, on rituals it is a prevailing tool to describe. As far as the context of the research was concerned, therefore, the instrument was thought as the best fit and virtually helpful to collect data in terms of quantity as well as quality. Furthermore, in its significance, observation found important evidence such social occasions.

\section{- Interviewing}

The interview was the second data gathering instrument. The tool had two parts: closed-ended and openended questionnaire. The closed-ended part was to record sex, age, residential area, \& etc. Moreover, open-ended interview questions were outlined in semi-structured form. Accordingly, the questions entirely focused on the use of proverbs on a daily basis. So the researcher had to tell and guide the focal participants, i.e., the individuals and groups of people as a means of checking over data accuracy retrieved from other tools. One-to-one or group interview was conducted among elderly residents. There were ten interview setting that lasted for an approximate of fifteen (15) to twenty (20) minutes. During the subsequent interviewing, the researcher was guiding the conversations to what extent they understood the role of proverbs.

\section{- Field notes}

The field notes were used to record events. It was scribbled at quick to catch up with events and later explored vi's-à-vi's to participants' point of views. Accordingly, data were written in shorthand. Later, after sometimes, the drafted information rearranged based on topical relevance. The behavior of the elders from the beginning of the scene of rituals, arbitrations, and the likes were registered, e.g., for any occurrence of evils or conflicts within a family, or neighbors or clans, and so forth, elders step in. The elderly, then try to investigate and review the matter. This culture has long been used as social control among the Oromos, and can't easily be violated. In all such occasions, proverbs play pivotal roles so that meanings can be easily implied and properly addressed.

\section{$>$ Population and Samples}

The target populations of this study were adults and elders who were the inhabitants of various residential areas or administrative units. Variables like gender and age were taken into considerations to select the representatives. The participants' age was thus between 40 and 89. Thus, samples were purposively selected based on the researcher's judgment call. The motive behind this (i.e., purposive sampling) was clear. As of the assessment being contacted, therefore, participants' communicative competence in general and sociolinguistic competence in particular was taken into consideration.

\section{- Participants}

The subjects of the study, as Table 3 below reveals, one hundred sixteen $(n=116)$ were participating in the study. The identification of the participants, i.e., age; gender; first language; socioeconomic status; level of education; and cultural competence were in the heading category so that variable data could be marked as of their separate data entry columns during data collection. The researcher then carefully departs from the culturally incompetent individuals. As long as the identity was concerned, tally mark was becoming a done deal. Double entries were carefully eliminated from the field notes being used with the help of marking with red pen. Below is therefore the summary of the count in accordance of their age, gender, and frequency.

\begin{tabular}{|c|c|c|c|c|c|c|c|c|c|c|c|c|}
\hline Age range & \multicolumn{2}{|c|}{$40-44$} & \multicolumn{2}{|c|}{$45-49$} & \multicolumn{2}{|c|}{$50-54$} & \multicolumn{2}{|c|}{$55-59$} & \multicolumn{2}{|c|}{$>60$} & \multicolumn{2}{|c|}{$(N=116)$} \\
\hline Gender & 1 & 2 & 1 & 2 & 1 & 2 & 1 & 2 & 1 & 2 & 1 & 2 \\
\hline Frequency & 21 & 17 & 16 & 12 & 31 & 9 & 6 & 0 & 4 & 0 & $78(67 \%)$ & $38(33 \%)$ \\
\hline Total & 381 & & 281 & $4 \%)$ & 40 & $5 \%)$ & & & & & 110 & $00 \%)$ \\
\hline
\end{tabular}

Key: [Gender: 1 = Male, $2=$ Female $]$

Table 1:- Participants' demographic information

As can be seen from the right side of the data given above, among $(N=116)$ of the participant, $(n=78(67 \%)$, male; $n=38(33 \%)$ female). Among these, as can be seen, $38(33 \%)$ of the age group fall into the 40 to 44 categories.
Similarly, 28(24\%) of the participants were in the age range of 45 and 49. Apparently, the overwhelming majority of the participants were between age 50 and 54 for the figure found out 40 (35\%). Participants aged between 55 and 59 
were figured out $6(5 \%)$, and then the total size of age above 60 was amounted $4(3 \%)$.

The inquisition had gone further as to dig out participants' first language, socioeconomic, education, and cultural competence. These variables were important to have the knowledge of what is what as far as proverbs are concerned. In accordance with the inquiry, all the participants speak the Oromo language as of their $\mathrm{L}_{1}$. Besides, their socioeconomic status was taken into consideration; in essence, participants whose income was from middle-to-low were chosen for the purpose of the study. Further, literacy level education and good level of cultural competence was considered to minimize hesitations in all affairs.

\section{- Sampling Techniques}

How was this part accomplished, and in what way? It was like this. Developing the sampling frame was relying on two basic criteria, that is, age and fame. The older the person the more likely that person would be selected. In accordance with these stated points of reference, a list box was developed so that the name, age and address of the participants were easily recognized from the inhabitants. Thus, purposive sampling was used to select the participants. In order to accomplish this therefore information was primarily assessed by the researcher, whether these elderly had enough knowledge of proverbs.

\section{Data Analysis Procedures}

The data analysis procedures begin by selecting and reducing the collected data to the manageable level. The data entirely based on describing the culture of using proverbs; indeed, the culture is proven to be the unit of analysis. Therefore, the thematic data from participant observation, interviewing and field notes were piled, selected and later analyzed verbally.

The instruments were used at different psychosocial settings of the inhabitants like religious/ritualistic, political, public, entertaining or festive, conciliatory etc. For instance, the participant observation ultimately helped the researcher to witness the proven wisdom of proverbs at various public occasions of the yaa'ii (which in the Oromo tongue means 'ritual').

Further, the interview was carried out on multiple occasions among more specifically among the 'abbaa gadaa' [to mean gadaa leader] and 'Kontoma' [i.e., highly ranked elder] that were having the responsibility of handling conflicts and closely monitoring situations. At last, some helpful information was being registered on the field notes of the researcher.

At the end, the analysis of the qualitative data was thoroughly done with the help of the coding system; accordingly, participants' confidentiality or privacy information was protected from data entry. Some variables gender, age, education, ethnicity, language, residential area, and so forth were found important to bear witness about the participants.

\section{RESULTS AND DISCUSSIONS}

There is a need to be clear on how to deal with this section as far as ethnographic study is entitled. In some books (e.g., Heigham \& Croker, 2009) this part or sections are not treated in compartment; rather, it is better to have them extended report in whole. By contrast, ethnography can be objectively based and scientifically written (e.g., Creswell, 2012). The latter is therefore used as a fundamental premise and a special obligation to this particular circumstance. Then, the results of the data are originated from three instruments. These are participant observation, ethnographic interviewing and field notes. In effect, the organization originates from results \& discussions.

\section{Results}

Below are the results of qualitative data.

\section{- Results of participant observation}

The proverbial saying 'Punctuality is the soul of business,' seemed to have proven on the date set out. Hence, the researcher is to provide what he saw in his own eyes and what hears in his own ears by taking part in the occasion. As the purpose had been primarily arranged by gadaa leaders, people were trickling beginning from the lit of the morning sun to the place where the nature was too lavish. Until they filled the sitewide, the arrivals had enjoyed sightseeing and gossiping affectionately. The grace of the crowed, together with, the large and adequate podocarpus, juniperus, hagenia and small vegetation was ineffable.

Whenever (e.g., draught hit, contagious disease, and so forth getting worse), they come together and demonstrate a meditative moment as of their culture. They plead, wish, and urge to their supernatural waaqaa (God) to avoid befalling of such evils. Thus, sooner everybody had got ready to pray, and a brief chanting of cultural songs came into being in harmony. Then, they started praying in chorus. The event was witnessing for no hypocrisy and no pretension to the following.

\section{$\checkmark$ Brevity}

Linguistic brevity is the conciseness, or the succinct power usually witnessed in proverbs. They aptly imply the meaning that the speaker wants to make. Accordingly, they have the supremacy of reinforcing what is being told off in a language order. That is why proverbs are often entertained by the natives in the attempt of consolidating meanings to targets.

\section{$\checkmark$ Acculturation}

Proverbs are being used to deepen the culture of the society so that the youth are cultured by the culturemakers, the gadaa leaders. They often use proverbs that include the beliefs, norms, attitudes, behaviors, expression, social wellbeing, and so forth. Soon the legendary gadaa leaders quieted of the noise; the youth occupied the front line of the gadaa leaders so as to be groomed in the art. Then, what? Two things to note: one, the youth will become 
independent, self-reliant, and value their cultural identity. Two, the community easily inherits its culture.

When the commencement of the program was fully undertaken; this time, the researcher was not only bearing witness the phenomena and but also capturing the exclusive developments with the help of eavesdropping, taperecording and. After the program, he took four groups of a size ten to twelve for data collection from the crowd. Indeed, many of the proverbs that were being told entered to contexts and values.

\section{Social control}

The other explicit connection between proverbs and contexts lies in the very characteristics of social control efforts. Everybody has to abide by the social obligations being imposed externally on such occasions. Proverbs further reinforce the gadaa leaders' speech; that is, to admonish the antisocial behavior and to cherish the desired ones. On this day, proverbs thus had long been knitting each and every announcement to the theme that was being made.

Antisocial behaviors are well-spoken in proverbs. One of the gadaa leaders, by holding green grasses and a horse whip together, in the hands of his said, "Namni jireenya isaa fakkaata." This means 'A person looks like his own living.' He explained the why of the proverb. He advised in authoritative language that everybody should and must carefully look after what the society needs to thrive. Soon afterwards, the elderly men subsequently came to the front, and said proverbs to excommunicate people in the contexts associated with psychopathic behaviors; for instance, murder and petty criminals like rudeness, mockery, theft, and so forth.

The gadaa leaders continued to advise the crowd. The other man in his erudition said, 'Lafaa tolanii, marqaa nyaatu.' This means 'If one takes care of the land, he will enjoy its fruit.' He continued the Gadaa system codes of practice, "According to Gadaa system," he said, "theft is evil; rules will have visited you! Manslaughter is evil; rules will have visited you! No one shuts down pedestrianly; calamity befalls you! Abduction is defiance; if any, rules will have visited you! Vengeance is a rebellion to these decrees; you are liable to punishment ...!" By this time, everybody got quiet.

The other gadaa leader, one of whom was a legendary person, started speaking in his stentorian voice in turn and said, "Once again quiet! Calm down! Quiet, Calm down! You wonder why we all here today!" He continued, "We all need a code to live by, guys!" Again the other gadaa leader continued in his proverb-filled speech. "Listen! 'Himan hima, yaadni abbaaf gala,' said the man. "It is an Oromo proverb that goes, "I speak the idea, and it's up to the person to understand." Listeners kept backchanneling as he spoke.

The gadaa leaders gave their unabated account on the nearly abandoned gadaa system rules. In the meantime, proverbs have been used to captivate loomed imaginations over the norm and culture of the Oromo people. As per the decree of the gadaa system, any indignant, if not to care of those decrees, shall be subjected to punishment. Subsequently, everybody gave a special attention since decisions will be enforced soon.

\section{$\checkmark$ Linguistic structure}

Linguistic structure of proverbs can be fallen into various categories; and therefore, as the deep and surface was significantly striking and enforcing so did all the structural elements. Thus, the researcher later tried to account three for each of them, i.e., simple, compound, complex, and compound-complex sentences. Hence, examples for each are as follows:

Simple

\begin{tabular}{|c|c|c|}
\hline S.N & Afan Oromo & Meaning \\
\hline 1 & Sussukuun(?) gulufa fida.(1) & Treading causes galloping. \\
\hline 2 & Namni waan arge dubbata.(1) & One speaks about what he has seen. \\
\hline 3 & Tufanii(?) hin arrabani.(1) & After spitting one doesn't lick the spittle. \\
\hline
\end{tabular}

Table 2:- Simple sentences

\section{Compound}

\begin{tabular}{|c|c|c|}
\hline S.N & Afan Oromo & Meaning \\
\hline 1 & Jabbiitu loon ta'a(1); ijoolletu nama ta'a(2). & A calf becomes herd, and so do the children to men. \\
\hline 2 & Sibiilli abbaan qare(1); abbaa qale(2). & One's sharped iron injured the person. \\
\hline 3 & Bunni afaan guba(1); yaadni garaa guba(2). & As coffee burns the mouth, thought does the stomach \\
\hline
\end{tabular}

Table 3:- Compound sentences 


\section{* Complex}

\begin{tabular}{|c|c|c|}
\hline S.N & Afan Oromo & Meaning \\
\hline 1 & Muka jigetti(1) qottoon baay'ata(2). & Where a tree falls axes increase. \\
\hline 2 & Jabbiin hootu(1) hin mar'attu(2). & A suckling calf never mows. \\
\hline 3 & Qaaqa kijibaa(1), jalatu qaawwa(2). & Under a liar's talk is a gap. \\
\hline
\end{tabular}

Table 4:- Complex sentences

\section{* Compound-complex}

\begin{tabular}{|c|c|c|}
\hline S.N & Afan Oromo & Meaning \\
\hline 1 & $\begin{array}{c}\text { Kan biyyaa dhaqe(1) } \\
\text { hinfakkaanneen(2) du'ee lafa haa } \\
\text { fakkaatuuree?(3) }\end{array}$ & $\begin{array}{c}\text { He went for the country; he died for what he doesn't resemble; } \\
\text { with the land then? }\end{array}$ \\
\hline 2 & $\begin{array}{c}\text { Arbi dhufe(1) faana dhawaa jennaan(2) faana maalii } \\
\text { qaaqxu(3) arbuu kunooti jedhe.(4) }\end{array}$ & $\begin{array}{c}\text { "The elephant has come; follow its footprint!" said one, but the } \\
\text { other said, "why you talk about the footprints if the elephant } \\
\text { itself is here." }\end{array}$ \\
\hline 3 & $\begin{array}{c}\text { Raafun sagal fuudhee(1) buddeena } \\
\text { sagal fuudhee(2) agabuu kiyyan } \\
\text { ba'e(3 jedhee namichi(4) }\end{array}$ & $\begin{array}{c}\text { "He took (ate) nine cabbages, he took nine bread, but "I went } \\
\text { out hunger" said the man. }\end{array}$ \\
\hline
\end{tabular}

Table 5:- Compound-complex

\section{- Results of the interview}

A series of interviews had been taking place at different settings among many men subdivided into groups. Each group comprises of $10-14$ men (12 on average). For the interview question, for instance, the interviewer and the interviewees had exchanged names before the interview. Then, the interviewer briefed them the overall theme of the study. Next, he encouraged the interviewees to cast-off trepidation, or a hesitation, or a concern as far as the research topic is concerned.

As the saying goes "Conversation is a game of circles," in most places, hence the interviewer and the interviewees sat in the way how conversations 'work'. Though it was normal, suspicion had been quite often while taping, or recording the voice of the interviewees. Hence, to reduce the circles of ambivalence, at different instances, the researcher tried to encourage and show his sincere honesty. In this connection, as the saying goes, 'He who inquires much, learns much' a solemn pledge was offered to initiate responses to the posed ethnographic (unstructured) questionnaire. Accordingly, the lessons being learnt are as follows:

\section{$\checkmark$ Why are proverbs?}

The respondents eventually replied in similar mentality. The question was entertained as a surprise. In most thoughts, the respondents expressed the essence of proverbs in terms their acculturation, brevity and social control. Similarly, their curiosity rested on soliciting the unweary contexts and values. In the course of inquiry, at different occasions, many of them were even replied with a proverbial language, 'Mammaaksi bifa dubbiiti, jabbiin bifa kormaati.' This means, 'A proverb entails the issue as a calf resembles the sire.'

\section{$\checkmark$ What challenges do you observe in people's use of proverbs?}

The question was posed to all members of the groups on several occasions. There were attributive responses to characterize people's behavior; however, they could be inferred from one or more of the following three factors: the mythical, the nativistic, and the editorial. To begin with, a person is said to be a good proverb speaker if and only if he or she is aged or adulthood stage. On the other hand, Hence, any aged person is efficient and knowledgeable about the overall aspect of proverbs. The fate of the speaker, as a myth, should necessarily be congruent to two crucial factors, that is, age and born

\section{$\checkmark$ What annoys you about Oromo proverbs?}

Start at the beginning of the inquiry, an elderly man answered so indignantly. Most researchers, as what the researcher of this study did, had merely collected proverbs in whatsoever, professionally or unprofessionally, they were all one to but made no difference yet to the destiny; or else, no one able to avail even a book-length to the kinship, i.e., free of potboiler works. They looked into another in astonishment. So, the other man added, what does it prove if no one seems to care of obligations? Are you waiting until their time of burial or vanishment? Their questions were not hard to accept, and neither was the reality. They sounded out a warning tone to the researcher, 'Enough is enough for talking the talk instead of walking the walk'. It was easy to understand this long term sense of anguish and despair across a continuum. Shortly, sometimes later, below was the quest that followed:

\section{$\checkmark$ What should be done?}

One of the elders spoke malevolently in his $\mathrm{L}_{1}$ proverb, 'Erga waraabessi darbee, sareen dutti' (which means 'After the hyena passes, the dog barks'). This is to mean, 'Too late to act'. They wish they had enough a bit earlier. A similar line of wishful criticism was given at 
different interview occasions. Needless to say, it was critical, if not cynical about kinship proverbs. Something must have done in the bygone days, but was not. Ultimately, it evoked the coercive idiom 'keep up with the Jones'. They offered an elderly advice to the prestigious intelligentsia to do their job with others in status. They explicate them to get off to the grassroots level to have collected from antecedents, the elderly.

To be honest, wherever the interviewer meets the interviewees, every now and then, suspicion and mistrust circulates as if nothing will come out of the interview. The interviewees were reluctant to communicate, and hopeless to pursue what the interviewer had been looking to have thence-after. After a plenty of sound discussions, at last, the interviewer shared their frustration, and appreciated their information.

\section{$\checkmark$ What advantages do we get?}

A wide range of ideas was given briefly within a few words. Thus, proverbs economize the language being used in conversations. On top of this, in case people won't need to be straightforward they use proverbs to imply. As they said, values are embedded to proverbs. For instance, they are blended happiness, dissatisfaction, threat, guilt, and so forth.

In human discourse, proverbs are being presented in different modes, i.e., at the start, at the middle and at last of perspectives being discussed.

\section{$\checkmark$ What kind of proverbs impacted your life?}

This interview question was posed to the interviewees so that they could be taken aback at recalling some proverbs they knew from past and present. As far as their life was concerned, then, they told many of them to the researcher. Accordingly, at the very least, hereinunder are particularly evidenced amongst the proverbs that impacted the life of the respondents, i.e., negatively or positively; direct or indirect; significant or insignificant; short-term or long-term. That wasn't useful to know, and for the purpose of the research investigation, a short list of these proverbs is presented as follows.

\section{- Results offield notes}

Below were the results of the study evidenced from excerpts of a field notes. Long days ago, at least on a weekly basis, the researcher often travelled to sites where there had been a sort of various social aspects. The researcher has come in contact with many people and kept interlingual rendition on the required information. Thus, some queries were posed to the respondents, and the whethersoever said of proverbs as a part and parcel they were recorded in field notes. Sooner or later they, as is indicated in the image data below, the all over the collection of the field notes was kept up safely in case they might help as data mining and auditing the results. As has repeatedly aforementioned in the study, the participants affirmed that proverbs seize on contexts that triggers of proverbs. Inevitably, in each of the proverbs there are coexisted values.

\section{$>$ Reliability}

How was the reliability issue? Reliability or the degree of consistency in the attempt of data findings has been checked and rechecked using the instruments. For instance, take the case of context and values being embedded in proverbs. The respondents have given similar reactions. They say, "Context is the fundamental premise to proverbs." They have a beautiful proverb to express this. That is, " Mammaaksi bifa dubbiiti; jabbileen bifa kormaati." This means, "A proverb resembles the issue being discussed as a calf resembles its sire."

\section{Validity}

The study is believed to be valid as far as its objectives are concerned. In the lounge thus the validity of the research has been carefully monitored so that the desired findings would be purported. In the attempt, what has been investigated inevitably show that proverbs are embedded with incalculable wisdom by which the society is to comply. In effect, therein are issues of brevity, acculturation, and social control.

\section{$>$ Discussions}

This part discusses the major findings of the study. In doing so, it was a compelling necessity, as many empirical evidences suggest, to put the researcher's 'self' into the study (e.g., Denscombe, 2007; Plano Clark \& Creswell, 2015). To witness the given accounts or phenomena, therefore, the researcher must reappear on various rituals, arbitrations, and occasions. Below is therefore the pictorial representation of context, value, and structure, whereas proverb is being used as a node of intersection for these elements.

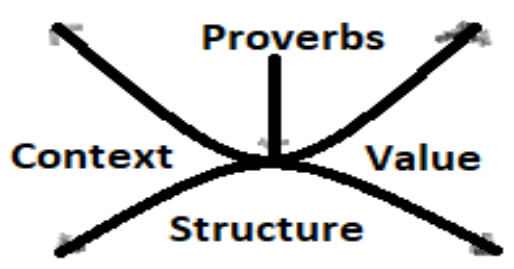

Fig 1:- Pictorial representation of context, value, and structure

Looking at the shape, in the figure above, there likely is a prospective question regarding its parabolic shape. However, the shape is to represent or indicate the ideas that are indirectly implied via proverbs. So there is a degree of flexibility in showing and understanding the meanings. Once again, it is important to understand that the vertical arrow offers the said intersection; but, proverbs rarely help to indicate straightforwardness to press a point of discussion in conversations. That seems enough justification for why the shape seems apparent. Therefore, proverbs in turn imply, and it is up to the listener to decipher meanings. 
Furthermore, most of the participants give an emphasis to the context and values being embedded in proverbs. At a time of data collection, when the researcher asked them to tell him a proverb, their answer was almost universal. They say, 'Bring a context and let it call proverbs to mind.' In the move, the following points of result have been evidenced:

- Proverbs are entirely based on reasons or contexts;.

- Societal values that are infixed in in a word or a phrase of proverbs;

- Proverbs play vital roles to further deepen cultural identity;

- Proverbs with archaic words compel the listener to hedge for meaning. To elucidate the point further, let us take the proverb of the language which was told to the researcher. 'Otteen ta mijigetti, haxumaan ta mijigetti, mooqqaan carree ceela.' Such proverbs, as can be seen in any other language, contain archaic words. The nearly word-by-word translation for this proverb is 'Pot the toiled, stirring wood the toiled, a spoon took melted butter.' Now its meaning is a bit clear.Therefore, getting the meaning of such proverbs in general and this proverb in particular is not as easy as it sounds.

- Proverbs carry multiple meanings; perhaps, based on Chomsky's Syntactic Structures - deep and surface structure can be mentioned here. Makkai \& Melby (1985) said, "In transformations rules we get two distinct levels of structural representation: 1) the level of structures generated by phrase-structure rules (called deep structures) and 2) the level of structures generated by transformations (called surface structures)" (p. 150). And thus, the ability to grasp the meaning of proverbs whether deep or surface needs strong socio-cultural background.

- Proverbs could backfire; therefore, one should think twice to speak apt to the context.

- Under the subsequent inquiry, the respondents articulate the culture of using proverbs is gradually diminishing; as a result, the amount of Oromo proverbs circulating in the society seems to dwindle as time goes on;

\section{CONCLUSIONS AND RECOMMENDATIONS}

\section{$>$ Conclusions}

So, what else is new? What rigorous conclusions can be made? Let us see the analysis of the quests. One, salient socio-cultural contexts call for a plenty of proverbs, and it is mandatory to use those proverbs thoroughly and precisely since one may contradict the other during conversations. And, two, multiple values are embedded in proverbs; for instance, loyalty, solidarity, dexterity, politeness, resilience, courage or bravery, and so forth. Three, like any elements of oral literature, proverbs are resilient to linguistic structure. These are with the prevailing of form and function.
- The Backlash:

The setbacks just seem to be two - the relevance and future concern.

$\checkmark$ Relevance is to mean that the irrelevant use of proverbs. In such proverbial utterances, the backfire could be enormous.

$\checkmark$ Negligence and marginalization of Oromo proverbs have remarkably been resulted in catastrophic effects; consequently, many of them were disinherited or vanished away.

\section{$>$ Recommendations}

A contemplation of the past not only reproofs repentance, but also increases queries and complaints as to the destiny of Oromo proverbs. Upon data collection, in many places, the participants expressed their disappointment. On the basis of these proven, evidences, therefore, the study suggests the following line of actions as recommendations:

- The study opens a window on the issue so that the intelligentsia can take multiangular views across the ORS. For instance, they can take insights into syntax, context, values and whatsoever else they like. This doesn't simply emanate from scholarly interest; rather, it is a parody reference, i.e., everywhere what the elders had been alarming.

- It is a high time to extricate institutions in place from abandonment. It has long been envisaged since the need to keep records or taking a count of Oromo proverbs mounting up. Thus, it seems important to do all the necessary things, including legendary elders, gadaa leaders, religious leaders, and so forth to ward off obsolescence from the present cultural intact. This enormous accountability needs careful planning and ancillary servicing from start to end (e.g., selection of centers, provision of resources, recruitment of the intelligentsia, and so forth).

- As of today, there are quite a number of reasons to be on the move; in essence, it is important to establish a task force for platform discussions at the ORS level. This group can assess Strength, Weakness, Opportunity and Threats (SWOT). For instance, this study suggests the establishment of "Proverbs Recount Standing Committee (PRSC)" to take registry centered on the grassroots involvement.

- Lastly, all the aforesaid facts are incumbent on three elements - the intelligentsia, the authorities, and the concerned institutions. Thus, strong cultural-centers can be established to execute the desired objectives.

\section{$>$ Implications of this study}

Plenty of worthwhile implications can be made; however, two of them are the following - theoretical implications and practical applications. 


\section{- Theoretical implications}

As has been said, proverbs liven up prevailing conversations. No matter what and no matter how situations are. It is possible to move forward in terms of quality and quantity, though a lot has left unanswered about Oromo proverbs. It does not come as a surprise. The most important of such a course of action is, perhaps, how to cope-up with the long- standing and profounding objection.

\section{- Practical implications}

It was a challenge to compromise a dire need that exists in the community-level and the desire for execution at the hierarchical level; as a consequence, what is best known is where the heart of the problem lies. It is in the continuing lack of action. In the areas where this study has been conducted, for instance, the multifaceted needs to support and to build moral virtues are enormous. The final issue is thus left up to the above-mentioned bodies for taking collective actions as a think tank. "If they weren't urbanely do it," asked one of the elderlys, "who would?" The study then evokes for practical move so that the intersection of proverbs, i.e., context, value, and syntax can be retained, or captured, or preserved.

\section{REFERENCES}

[1]. Ananda,T .(1995). Peace is a Fire: A Collection of Writings and Sayings. Sangharakshita: Windhorse Publications

[2]. Bauman, R (1983). The field study of folklore in context. Bloomington: Indiana University Press

[3]. Bauman, R. \& Briggs, Ch. (1990). Poetics and performance as critical perspectives on language and social life. Annual Review of Anthropology 19. 59-88.

[4]. Baxter, P., Hultin, J. \& Truizi, A. (1996). Being and Becoming Oromo: Historical and Anthropological Enquiries. Stockholm: The Red Sea Press, Inc.

[5]. Biehl, J. \& Good, B. (2007).Subjectivity: Ethnographic Investigations. Berkeley: University of California Press

[6]. Brinton, L. (2000). The Structure of Modern English: A linguistic introduction. Amsterdam: John Benjamins Publishing Company

[7]. Brown, D. (2000). Principles of Language Learning and Teaching. New York: Longman

[8]. Brown, K. \& Miller, J. (2013).The Cambridge Dictionary of Linguistics. Cambridge: CUP

[9]. Bruce, St. \& Yearley, St.(2006).The Sage Dictionary of Sociology. London: SAGE Publications

[10]. Chomsky, N. (2006). Language and Mind. Cambridge: Cambridge University Press

[11]. Collins, J. \& Patricia, N. (2003). The Greenwood Dictionary of Education. New York: Greenwood Press

[12]. Cotter, G. (1990). Salt for Stew. Debre Zeit: Markynoll Fathers

[13]. Coultas, A. (2003). Language and Social contexts. London and New York: Routledge

[14]. Creswell, J.W. (2012). Educational Research: Planning, Conducting, \& Evaluating Quantitative and Qualitative Research. Boston: Pearson Education, Inc.
[15]. Dominguez, E. (2010). The Function of Proverbs in Discourse: The Case of a Mexican Transnational Social Network. New York: De Gruyter Mouton

[16]. Denscombe, M. (2007). The Good Research Guide for small-scale social research projects. New York: McGraw-Hill

[17]. Dörnyei, Z. (2007). Research Methods in Applied Linguistics: Quantitative, Qualitative and Mixed Methodologies. Oxford: Oxford University Press

[18]. Finnegan, R. (2012). Oral Literature in Africa: World Oral Literature Series: Volume 1. Cambridge: Open Book Publishers

[19]. Gondin, W. \& Mammen, E. (1970). The Art of Speaking. London: W.H Allen Company.

[20]. Halliday, M.A.K. (2007). Language and Education. London: Continuum.

[21]. Harklau, L. (2005). 'Ethnography and ethnographic research on second language teaching and learning' in E.Hinkel(ed). Handbook of Research in Second Language Teaching and Learning. Mahwah, N.J.: Lawrence Erlbaum (cited in Dörnyei 2007).

[22]. Hartwell, J. (2008).Encyclopedia of Race and Racism: Volume 1. Detroit: Thomson

[23]. Heigham, J. \& Croker, R. (2009). Qualitative Research in Applied Linguistics: A Practical Introduction. New York: Palgrave Macmillan.

[24]. Hinkel, E. (2004). Teaching Academic ESL Writing: Practical Techniques in Vocabulary and Grammar. London: LAWRENCE ERLBAUM ASSOCIATES, PUBLISHERS

[25]. Holtgraves, Th. (2002).Language as Social Action: Social Psychology and Language use. New Jersey: Lawrence Erlbaum Associates, Publishers

[26]. J. Webster, J. (2008). Meaning in Context: Strategies for Implementing Intelligent Applications of Language Studies. New York: continuum

[27]. Kelly, J. (2017). Teaching and Researching Language and Culture. New York and London: Routledge

[28]. Kleinman, A. (2006). What Really Matters: Living a Moral Life Amidst Uncertainty and Danger. Oxford: Oxford University Press

[29]. Leavy, P. (2017). Research Design: Quantitative, Qualitative, Mixed Methods, Arts-Based, and Community-Based Participatory Research Approaches. New York \& London: The Guilford press

[30]. LeCompte, M. \& Schensul, J. (2010 ). Designing \& Conducting Ethnographic Research: An Introduction. New York: Rowman \& Littlefield Publishers, Inc.

[31]. Makkai, A. \& Melby, A. (1985). Linguistics and Philosophy. Amsterdam: John Benjamins Publishing Company

[32]. Manser, M. (2007). The Facts On File Dictionary of Proverbs. New York: Library of Congress

[33]. McCarthy, M. (2000). Discourse Analysis for Language Teachers. Cambridge. CUP

[34]. Mieder, W. (2004). Proverbs: A Handbook. London: Greenwood Press

[35]. Montgomery, M. \& et al. (2007). Ways of Reading: Advanced reading skills for students of English literature. London and New York: Routledge 
[36]. Mullany, L. \& Stockwell, P. (2010).Introducing English Language: A resource book for students. London and New York: Routledge

[37]. Murray, N. \& Hughes, G.(2008). Writing up your University Assignments and Research Projects: A practical handbook. Berkshire: McGraw-Hill.

[38]. Olson, D. (2000). From Utterance to Text: The bias of language in speech and writing. Massachusetts: Harvard University

[39]. Plano Clark, L. \& Creswell, J.W., (2015). Understanding Research: A Consumer's Guide. Boston: Pearson

[40]. Richards, J. \& Schmidt, R. (2002). Longman Dictionary of Language Teaching and Applied Linguistics. London: Longman

[41]. Risager, K. (2007). Language and Culture Pedagogy: From a National to a Transnational Paradigm. Toronto: Multilingual Matters Ltd.

[42]. Ritchie, J. \& Lewis, J. (2003). Qualitative Research Practice: A Guide for Social Science Students and Researchers. London: SAGE Publications

[43]. Roth, E. \& Aberson, T. (2008). Compelling Conversations: Questions and Quotations on Timeless Topics. Charleston: Chimayo Press

[44]. Rowoldt, S. (2018).The Odyssey of the Oromo Slaves from Ethiopia to South Africa. Athens: Ohio University Press

[45]. Seitel, P. (1999).The Powers of Genre: Interpreting Haya Oral Literature. Oxford: Oxford University Press

[46]. Silverman, D. (2003). Qualitative Research: Theory, Method and Practice. London: SAGE Publications

[47]. Smith, P. \& Pellegrini, A. (2000). Psychology of Education: Major Themes, Vol. III. London and New York: Routledge

[48]. Spencer-Oatey, H. \& Franklin, P.(2009). Intercultural Interaction: A Multidisciplinary Approach to Intercultural Communication. New York: PALGRAVE MACMILLAN

[49]. Stone, J. R (2006). The Rutledge Book of World Proverbs. London and New York: Routledge

[50]. Sumner, C. (1996). Oromo Wisdom Literature, Volume 1 Proverbs Collection and Analysis Addis Ababa: Gudina Tumsa Foundation

[51]. _ (1996). Proverbs, Songs, Folk Tales An Anthology of Oromo Literature Addis Ababa: Gudina Tumsa Foundation

[52]. Tankersley, D. (2006). Teachers' Guide Educating for Diversity: Education for Social Justice Activities for Classrooms. Washington:International Step by Step Association

[53]. Tavakoli, H. (2012). A Dictionary of Research Methodology and Statistics in Applied Linguistics. Tehran: RAHNAMA PRESS

[54]. Yin, R. (2011).Qualitative Research from Start to Finish. New York: The Guilford Press 